\title{
Research
}

\section{Management of miscarriage: expectant, medical, or surgical? Results of randomised controlled trial (miscarriage treatment (MIST) trial)}

\author{
J Trinder, P Brocklehurst, R Porter, M Read, S Vyas, L Smith
}

\begin{abstract}
Objective To ascertain whether a clinically important difference exists in the incidence of gynaecological infection between surgical management and expectant or medical management of miscarriage.

Design Randomised controlled trial comparing medical and expectant management with surgical management of first trimester miscarriage.

Setting Early pregnancy assessment units of seven hospitals in the United Kingdom.

Participants Women of less than 13 weeks' gestation, with a diagnosis of early fetal demise or incomplete miscarriage. Interventions Expectant management (no specific intervention); medical management (vaginal dose of misoprostol preceded, for women with early fetal demise, by oral mifepristone 24-48 hours earlier); surgical management (surgical evacuation).

Main outcome measures Confirmed gynaecological infection at 14 days and eight weeks; need for unplanned admission or surgical intervention.

Results 1200 women were recruited: 399 to expectant management, 398 to medical management, and 403 to surgical management. No differences were found in the incidence of confirmed infection within 14 days between the expectant group (3\%) and the surgical group (3\%) (risk difference $0.2 \%$, $95 \%$ confidence interval $-2.2 \%$ to $2.7 \%$ ) or between the medical group (2\%) and the surgical group $(0.7 \%,-1.6 \%$ to $3.1 \%)$. Compared with the surgical group, the number of unplanned hospital admissions was significantly higher in both the expectant group (risk difference $-41 \%,-47 \%$ to $-36 \%$ ) and the medical group $(-10 \%,-15 \%$ to $-6 \%)$. Similarly, when compared with the surgical group, the number of women who had an unplanned surgical curettage was significantly higher in the expectant group (risk difference $-39 \%,-44 \%$ to $-34 \%$ ) and the medical group $(-30 \%,-35 \%$ to $-25 \%)$.

Conclusions The incidence of gynaecological infection after surgical, expectant, and medical management of first trimester miscarriage is low (2-3\%), and no evidence exists of a difference by the method of management. However, significantly more unplanned admissions and unplanned surgical curettage occurred after expectant management and medical management than after surgical management. Trial registration National Research Register: N0467011677/N0467073587.
\end{abstract}

\section{Introduction}

Approximately 1 in 9 pregnancies end in spontaneous first trimester miscarriage. ${ }^{1}$ Diagnosis of miscarriage has traditionally been followed by surgical curettage, on the assumption that this decreases the risk of subsequent gynaecological infection. However, surgical management is not without complications. ${ }^{2}$

Other management options (expectant or medical) have been offered to women with a miscarriage. Expectant management allows spontaneous passage of retained products of conception, and medical management uses drugs to aid expulsion of retained products. The optimal management for two common types of miscarriage, incomplete miscarriage and early fetal demise (previously termed "missed" miscarriage), is uncertain. $^{34}$

Three small randomised controlled trials have compared expectant management and surgical management of miscarriage. ${ }^{5-7}$ Expectant management was found to result in complete uterine evacuation over three days in $79 \%$ of cases of incomplete miscarriage. ${ }^{6}$ However, efficacy was reduced to $37 \%$ after seven days when expectant management was used to treat women with miscarriage mostly diagnosed as early fetal demise. ${ }^{7}$ These trials found no differences in the number of complications between surgical and expectant management, but the trials were small with a total of 186 women allocated to expectant management.

Medical management has also been used as an alternative to surgical management. Treatment regimens include the use of the antiprogesterone, mifepristone, and a prostaglandin analogue, the most commonly used of which is misoprostol. Nine randomised controlled trials have compared medical and surgical management. ${ }^{28-15}$ Success rates as low as $13 \%$ and as high as $93 \%$ have been reported in small trials. ${ }^{8} 3$ As with the observational studies, the trials used differing drug regimens and different measures of success.

Data are lacking from large randomised controlled trials assessing which management option is best for managing miscarriage with respect to complete emptying of the uterine cavity and subsequent uterine infection. Randomised controlled trials have largely been unsuccessful in recruiting large numbers of women, as recruiting women at such an emotional time is difficult and as many as 8 in 9 women express a definite preference for treatment and decline randomisation. ${ }^{16}$ Only one other trial has assessed all three treatment options; it was curtailed after only 40 women were randomised owing to recruitment difficulties. $^{17}$ The aim of the miscarriage treatment (MIST) trial, 
therefore, was to compare both medical and expectant management with usual (surgical) management of early miscarriage.

\section{Methods}

This was a multicentre trial with seven participating hospitals, each of which had an early pregnancy clinic. Recruitment started in May 1997 and finished in December 2001. Written consent was obtained for each patient.

\section{Eligibility criteria}

Women with a pregnancy of less than 13 weeks' gestation who had been diagnosed as having either an incomplete miscarriage or early fetal/embryonic demise were eligible. Exclusion criteria were severe haemorrhage or pain, pyrexia above $37.5^{\circ} \mathrm{C}$, severe asthma, haemolytic disease or blood dyscrasias, current anticoagulation or systemic corticosteroid treatment, twin or higher order pregnancy, smoker aged over 35, and inability to understand written English.

We defined early embryonic demise as an intact gestation sac of greater than $20 \mathrm{~mm}$ mean diameter with no other internal structures and early fetal demise as a fetus of over $6 \mathrm{~mm}$ crownrump length with no heart activity on transvaginal ultrasound scan. ${ }^{18}$ We defined an incomplete miscarriage as areas of mixed echogenicity within the uterine cavity with or without a disordered gestation sac.

\section{Randomisation and blinding}

Randomisation was by a central telephone system at the Clinical Trials Services Unit, Oxford. We used minimisation to ensure comparability between women with respect to participating centre, parity, type of miscarriage, and gestation.

\section{Interventions}

We gave all women a specific information sheet, 30 co-dydramol tablets, and an emergency telephone number. Women in the expectant management arm were allowed home with no intervention. In the medical management arm, women with an incomplete miscarriage were admitted to hospital and given a single vaginal dose of $800 \mu \mathrm{g}$ misoprostol. ${ }^{19}{ }^{20}$ Women with early fetal or embryonic demise were pre-treated with a single oral dose of $200 \mathrm{mg}$ mifepristone, ${ }^{21}$ then admitted to hospital 24-48 hours later for a single vaginal dose of $800 \mu \mathrm{g}$ misoprostol. A surgical evacuation of retained products of conception was offered if expulsion of retained products had not started within eight hours of insertion of misoprostol. Women in the surgical management arm were admitted for surgical suction curettage under general anaesthesia. No centre used prophylactic antibiotics at the time of curettage.

In all three groups, blood was taken for full blood count. Rhesus negative women were offered 250 IU of anti-D irrespective of their allocated management. A follow-up appointment was arranged 10-14 days after trial entry for a transvaginal ultrasound scan, full blood count, consultation with the study nurse, and examination by a gynaecologist if symptoms of infection were present. Retained products of conception were diagnosed if areas of mixed echogenicity within the uterine cavity were seen. A surgical curettage was offered if retained products of conception were present. Clinical symptoms were also taken into account; individual doctors in the early pregnancy clinics made the decision to offer curettage, in association with the women.

\section{Study hypothesis}

Our study hypothesis was that a clinically important difference would exist in documented gynaecological infection within 14 days of expectant or medical management compared with surgical management of first trimester miscarriage.

\section{Outcomes}

The primary outcome was documented gynaecological infection within 14 days of trial entry, defined as two or more of purulent vaginal discharge, pyrexia $>38.0^{\circ} \mathrm{C}$, tenderness over the uterus on abdominal examination, and a white cell count above $15 \times 10^{9} / 1$. Secondary outcomes were treatment with antibiotics for presumed gynaecological infection within 14 days and within eight weeks; duration of clinical symptoms (pain, additional analgesia, vaginal bleeding, days off work, days before return to usual daily activities); complications (fall in haemoglobin at 10-14 days, blood transfusion, unplanned consultations or admissions within 14 days and within eight weeks); efficacy-we defined a successful outcome as no unplanned surgical curettage within eight weeks; psychological outcomes (depression and anxiety on the hospital anxiety and depression scale at eight weeks); and return to normal activity (standard UK SF-36).

\section{Sample size estimation}

On the basis of the one published trial before the MIST trial started, we expected the incidence of the primary outcome in the standard care group (surgical management) to be $10 \%{ }^{6}$ To detect a $50 \%$ lower incidence of this outcome in the surgical group, compared with the expectant or medical management group, we needed to recruit 474 women to each group, giving a total sample size of 1422 women. This sample size would have $80 \%$ power to detect the treatment effect significant at the $5 \%$ level.

\section{Statistical methods}

We used SPSS to analyse data. We express the differences between groups as risk differences with 95\% confidence intervals.

\section{Trial management}

A research fellow (JT) based at one of the centres coordinated the day to day activity of the seven participating centres. Randomisation, data management, and analyses were done at the National Perinatal Epidemiology Unit, Oxford. A multidisciplinary steering committee oversaw the trial. We established an independent data monitoring committee, which met annually during the period of recruitment to review interim analyses; its terms of reference stated that interim results should not be revealed to the steering committee unless a strong reason to alter the protocol or stop the trial emerged.

\section{Results}

\section{Participant recruitment, flow, and follow-up}

Of 3905 women attending the early pregnancy clinics, we recruited and randomised 1200 (31\%) women (figure); 1620 women refused trial entry and were offered routine surgical management; 1085 women were not eligible for entry to the study. The number of women recruited to the trial was lower than that needed to meet the original sample size calculation. Recruitment was slower than anticipated and despite an additional 33 months of recruitment, we recruited a total of 1200 women. Two women recruited to the trial were subsequently found to have a viable pregnancy. No important baseline differences were evident between the three groups (table 1).

Of the 402 women randomised to surgical management, 356 $(89 \%)$ had a surgical curettage. Among the 46 women who did not have elective curettage, $30(8 \%)$ miscarried before admission and $16(4 \%)$ declined to have curettage after randomisation; 
Table 1 Characteristics of participants at trial entry. Values are numbers (percentages) unless stated otherwise

\begin{tabular}{lccc} 
Characteristic & Surgical $(\mathbf{n}=\mathbf{4 0 2})$ & Expectant $(\mathbf{n}=\mathbf{3 9 8})$ & Medical $(\mathbf{n}=\mathbf{3 9 8})$ \\
\hline Mean (SD) age (years) & $31.5(5.8)$ & $31.3(5.8)$ & $31.2(5.9)$ \\
\hline Gestational age (days): & $25(6)$ & $26(7)$ & $18(5)$ \\
\hline$<56$ & $173(43)$ & $168(42)$ & $168(42)$ \\
\hline 56 to 76 & $147(37)$ & $147(37)$ & $155(39)$ \\
\hline 77 or more & $57(14)$ & $57(14)$ & $57(14)$ \\
\hline Not known & & & \\
\hline Parity: & $175(44)$ & $170(43)$ & $172(43)$ \\
\hline Nulliparous & $227(56)$ & $228(57)$ & $226(57)$ \\
\hline Parous & $310(77)$ & $306(77)$ & $308(77)$ \\
\hline Type of miscarriage: & $92(23)$ & $92(23)$ & $90(23)$ \\
\hline Missed & $335(83)$ & $340(85)$ & $331(83)$ \\
\hline Incomplete & $205(51)$ & $213(54)$ & $206(52)$ \\
\hline $\begin{array}{l}\text { Bleeding at entry } \\
\text { Pain }\end{array}$ & $21.0(14-29)$ & $21.0(14-30)$ & $21.0(14-30)$ \\
\hline $\begin{array}{l}\text { Median (interquartile range) } \\
\text { anterioposterior diameter } \\
\text { on ultrasound scan }\end{array}$ & & &
\end{tabular}

however, 12 (3\%) subsequently had curettage. In 12 (3\%) women in the medical group, the miscarriage occurred spontaneously before admission (2 (0.5\%) subsequently had curettage).

\section{Gynaecological infection}

We found no difference in the primary outcome measure-that is, the incidence of infection within the first 14 days-between the expectant group and the surgical group or between the medical group and the surgical group-surgical group 3\% (12/402), expectant group 3\% (11/398), medical group 2\% (9/398) (table 2). The incidence of infection defined as prescription of antibiotic for presumed gynaecological infection within the first 14 days was significantly lower in the expectant group $(17 / 398)$ compared with the surgical group (34/402) (risk difference 4\%, $95 \%$ confidence interval $1 \%$ to $8 \%$ ). The incidence of this outcome in the medical group (31/398) was not significantly different from that in the surgical group (risk difference 1\%,-3\% to $5 \%$ ). We found no significant difference at eight weeks for either group compared with the surgical group.

\section{Unplanned hospital consultation and admissions}

The number of unplanned hospital consultations (without admission), both within the first 14 days after randomisation and within the first eight weeks, was similar for all management groups. However, the number of unplanned hospital admissions was significantly higher in the expectant group $(196,49 \%)$ than in the surgical group $(32,8 \%)$ (risk difference $-41 \%,-47 \%$ to

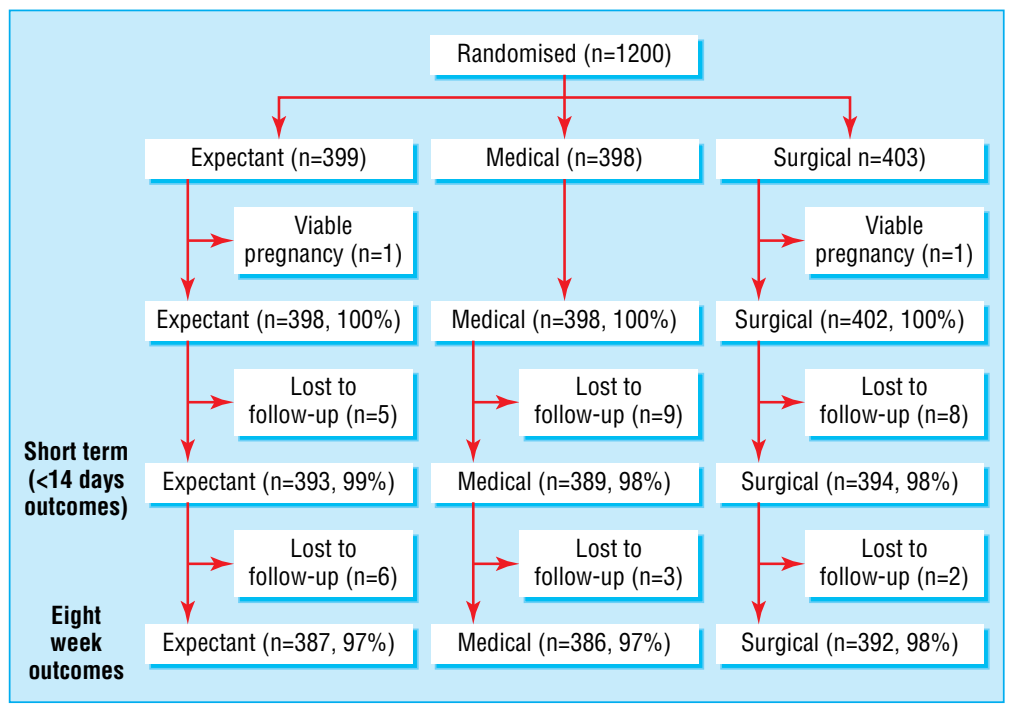

Flow of patients through MIST trial

Table 2 Clinical outcomes. Values are numbers (percentages) unless stated otherwise

\begin{tabular}{|c|c|c|c|c|c|}
\hline Outcome & Surgical $(n=402)$ & Expectant $(\mathrm{n}=398)$ & $\begin{array}{l}\text { Surgical-expectant } \% \text { risk difference }(95 \% \\
\text { CI) }\end{array}$ & Medical $(\mathrm{n}=398)$ & $\begin{array}{l}\text { Surgical-medical risk difference } \\
(95 \% \mathrm{Cl})\end{array}$ \\
\hline \multicolumn{6}{|l|}{ Infection specified by criteria: } \\
\hline By $10-14$ day follow-up & $12(3)$ & $11(3)$ & $0.2(-2.2$ to 2.7$)$ & $9(2)$ & 0.7 (-1.6 to 3.1$)$ \\
\hline By 8 week follow-up & $16(4)$ & $14(4)$ & $0.5(-2.3$ to 3.2$)$ & $12(3)$ & $1.0(-1.7$ to 3.7$)$ \\
\hline \multicolumn{6}{|l|}{ Infection specified by antibiotic use: } \\
\hline By $10-14$ day follow-up & $34(8)$ & $17(4)$ & $4.2(0.8$ to 7.7$)$ & $31(8)$ & $0.7(-3.2$ to 4.5$)$ \\
\hline By 8 week follow-up & $44(11)$ & $31(8)$ & $3.2(-0.9$ to 7.3$)$ & $43(11)$ & $0.1(-4.2$ to 4.5$)$ \\
\hline \multicolumn{6}{|l|}{ 10-14 day follow-up ultrasound scan: } \\
\hline Evidence of RPOC & $41(10)$ & $145(36)$ & $-26.2(-31.7$ to -20.6$)$ & $78(20)$ & $-9.4(-14.3$ to -4.5$)$ \\
\hline Equivocal result & $53(13)$ & $42(11)$ & $2.6(-1.9$ to 7.1$)$ & $52(13)$ & $0.1(-4.6$ to 4.8$)$ \\
\hline Empty uterus & 271 (67) & $185(46)$ & 20.9 (14.1 to 27.5) & $240(60)$ & 7.1 (0.5 to 13.7) \\
\hline No follow-up scan & $37(9)$ & $26(7)$ & $2.7(-1.1$ to 6.5$)$ & $28(7)$ & $2.2(-1.7$ to 6.0$)$ \\
\hline $\begin{array}{l}\text { Median (interquartile range) duration of } \\
\text { bleeding (days) }\end{array}$ & $8(4-14)$ & $12(7-15)$ & & $11(7-15)$ & \\
\hline Blood transfusion & 0 & $7(2)$ & $-1.8(-3.6$ to -0.4$)$ & $4(1)$ & $-1.0(-2.6$ to 0.4$)$ \\
\hline Extra analgesia taken & $71(18)$ & $177(44)$ & $-26.8(-32.8$ to -20.5$)$ & $98(25)$ & $-7.0(-12.6$ to -1.3$)$ \\
\hline
\end{tabular}

$\mathrm{RPOC}=$ retained products of conception. 
Table 3 Details of women who had unplanned curettage. Values are numbers (percentages) unless stated otherwise

\begin{tabular}{|c|c|c|c|c|c|}
\hline Outcome & Surgical (n=402) & Expectant $(\mathrm{n}=398)$ & $\begin{array}{l}\text { Surgical-expectant \% risk } \\
\text { difference }(95 \% \mathrm{CI})\end{array}$ & $\begin{array}{r}\text { Medical } \\
(\mathrm{n}=398)\end{array}$ & $\begin{array}{l}\text { Surgical-medical \% risk } \\
\text { difference }(95 \% \mathrm{Cl})\end{array}$ \\
\hline No of women who had any curettage* & $356(89)$ & $177(44)$ & 44.1 (38.1 to 49.6) & $142(36)$ & 52.9 (46.9 to 58.2) \\
\hline $\begin{array}{l}\text { No of women who had one or more unplanned } \\
\text { curettaget }\end{array}$ & $22(5)$ & $177(44)$ & $-39(-44.2$ to -33.5$)$ & $52(13)$ & $-7.6(-11.7$ to -3.6$)$ \\
\hline \multicolumn{6}{|l|}{ Timing of first unplanned curettage: } \\
\hline Before 10-14 day follow-up & $14(3)$ & $94(24)$ & $-20.1(-24.8$ to -15.6$)$ & $20(5)$ & $-1.5(-4.5$ to +1.3$)$ \\
\hline 10-14 day follow-up or after & $8(2)$ & $82(21) \ddagger$ & $-18.6(-23.0$ to -14.5$)$ & $32(8)$ & $-6.1(-9.3$ to -3.1$)$ \\
\hline \multicolumn{6}{|c|}{ Main reason for unplanned consultation resulting in first unplanned curettage: } \\
\hline Excess bleeding & $7(2)$ & $22(6)$ & $-3.8(-6.6$ to -1.2$)$ & $12(3)$ & $-1.3(-3.6$ to -0.09$)$ \\
\hline Pain & $3(1)$ & $5(1)$ & $-0.5(-2.2$ to +1.1$)$ & $3(1)$ & $0(-1.5$ to 1.5$)$ \\
\hline Patient request & $2(0)$ & $60(15)$ & $-14.6(-18.4$ to -11.1$)$ & $10(3)$ & $-2.0(-4.1$ to -0.03$)$ \\
\hline Retained products on scan & $8(2)$ & $72(18)$ & $-16.1(-20.3$ to -12.1$)$ & $24(6)$ & $-0.4(-0.7$ to -1.3$)$ \\
\hline Other & $2(0)$ & $17(4) \ddagger$ & $-2.0(-4.1$ to -.03$)$ & $3(1)$ & $-0.03(-1.7$ to 1.1$)$ \\
\hline $\begin{array}{l}\text { No of women who had more than one unplanned } \\
\text { curettage (total) }\end{array}$ & $2(0)$ & $10(3)$ & $-3.8(-6.3$ to -1.7$)$ & $2(1)$ & $0(-1.4$ to 1.3$)$ \\
\hline
\end{tabular}

*Allocated, for failed medical induction, or unplanned.

†Excluding women who had curettage for failure of medical management protocol.

łOne not known.

$-36 \%)$ and was also higher in the medical group (72, 18\%) $(-10 \%,-15 \%$ to $-6 \%)$.

\section{Unplanned curettage}

Table 3 shows the number of women who had unplanned surgical curettage and the indications. One hundred and forty two $(36 \%)$ women randomised to medical management had surgical curettage compared with $22(5 \%)$ women who had unplanned curettage in the surgical group (risk difference $-30 \%,-35 \%$ to $-25 \%$ ). Of 142 women in the medical group who had curettage, the indication for this was failure of the medical management protocol in 90 (23\%). A further 52 (13\%) women had an unplanned curettage, $11(3 \%)$ as an emergency procedure before anticipated admission.

The type of miscarriage was a factor in the success of management. Twenty $(6 \%)$ women with early fetal demise who were allocated to the surgical group had an unplanned curettage, compared with a total of $116(38 \%)$ of the medical group (risk difference $-31 \%,-37 \%$ to $-25 \%$ ) and $154(50 \%)$ of the expectant group $(-44 \%,-50 \%$ to $-37 \%)$ (table 4 ). Of women with an incomplete miscarriage, $2(2 \%)$ in the surgical group had an unplanned curettage compared with a total of 26 $(29 \%)$ in the medical group (risk difference $-27 \%,-37 \%$ to $-17 \%)$ and $23(25 \%)$ in the expectant group $(-23,-33 \%$ to $-13 \%$ ) (table 5).

\section{Clinical symptoms, complications, and side effects}

Cessation of bleeding after randomisation was significantly earlier in the surgical group than in the medical group $(\mathrm{P}=0.0004)$ and the expectant group $(\mathrm{P}<0.0001)$, but this did not affect haemoglobin concentration and haematocrit at 10-14 days. However, 7 (2\%) women randomised to expectant management and $4(1 \%)$ women randomised to medical management had a blood transfusion. No women randomised to surgical management had transfusions.

We found no significant difference in vomiting, diarrhoea, or pain (when assessed by the medical staff) in the medical group compared with the surgical group. We used the outcome of

Table 4 Selected outcomes for women with early fetal demise. Values are numbers (percentages) unless stated otherwise

\begin{tabular}{|c|c|c|c|c|c|}
\hline Outcome & $\begin{array}{r}\text { Surgical } \\
(\mathrm{n}=310)\end{array}$ & Expectant $(n=306)$ & $\begin{array}{l}\text { Surgical-expectant } \% \text { risk } \\
\text { difference }(95 \% \mathrm{Cl})\end{array}$ & $\begin{array}{r}\text { Medical } \\
(\mathrm{n}=308)\end{array}$ & $\begin{array}{c}\text { Surgical-medical \% risk difference } \\
(95 \% \mathrm{CI})\end{array}$ \\
\hline \multicolumn{6}{|l|}{ Infection specified by criteria: } \\
\hline By 10-14 day follow-up & $9(3)$ & $9(3)$ & 0 (-2.9 to 2.8$)$ & $7(2)$ & $0.06(-2.1$ to 3.4$)$ \\
\hline \multicolumn{6}{|l|}{ Infection specified by antibiotic use: } \\
\hline By 10-14 day follow-up & $26(8)$ & $15(5)$ & $3.5(-0.05$ to 7.6$)$ & $25(8)$ & $0.03(-4.2$ to 4.7$)$ \\
\hline By 8 week follow-up & $33(11)$ & $28(9)$ & $1.5(-3.3$ to 6.3$)$ & $34(11)$ & $-0.04(-5.4$ to 4.6$)$ \\
\hline $\begin{array}{l}\text { No of women who had one or more unplanned } \\
\text { curettage } \dagger\end{array}$ & $20(6)$ & $154(50)$ & $-43.9(-49.9$ to -37.4$)$ & $46(15)$ & $-8.5(-13.4$ to -3.6$)$ \\
\hline \multicolumn{6}{|c|}{ Main reason for unplanned consultation resulting in unplanned curettage: } \\
\hline Excess bleeding & $5(2)$ & $15(5)$ & $-3.3(-6.5$ to 0.04$)$ & $12(4)$ & $-2.3(-5.2$ to 0.04$)$ \\
\hline Pain & $3(1)$ & $5(2)$ & $0.07(-2.9$ to 1.4$)$ & $3(1)$ & $0(-2.0$ to 1.9$)$ \\
\hline Patient request & $2(1)$ & $52(17)$ & $-16.3(-21.0$ to -12.2$)$ & $8(3)$ & $-2.0(-4.4$ to 0.2$)$ \\
\hline Retained products on scan & $8(3)$ & $64(21)$ & $-18.3(-23.4$ to -13.5$)$ & $21(7)$ & $-4.2(-7.8$ to -0.09$)$ \\
\hline Other & $2(1)$ & $17(6) \ddagger$ & $-4.9(-0.81$ to -2.3$)$ & $2(1)$ & $0(-1.8$ to 1.7$)$ \\
\hline Median (interquartile range) duration of bleeding (days) & $9(4.8-14)$ & $12(7-16)$ & & $11(7-15)$ & \\
\hline Blood transfusion & 0 & $7(2)$ & & $3(1)$ & \\
\hline Extra analgesia taken & $59(19)$ & $156(51)$ & $-31.9(-38.8$ to -24.6$)$ & $82(27)$ & $-7.6(-14.1$ to -1.0$)$ \\
\hline
\end{tabular}

*Allocated, for failed medical induction, or unplanned.

†Excluding women who had curettage for failure of medical management protocol.

fOne not known. 
Table 5 Selected outcomes for women with incomplete miscarriage. Values are numbers (percentages) unless stated otherwise

\begin{tabular}{|c|c|c|c|c|c|}
\hline Outcome & Surgical $(n=92)$ & Expectant $(\mathrm{n}=92)$ & $\begin{array}{l}\text { Surgical-expectant \% risk } \\
\text { difference }(95 \% \mathrm{CI})\end{array}$ & Medical $(n=90)$ & $\begin{array}{l}\text { Surgical-medical \% risk difference } \\
(95 \% \mathrm{CI})\end{array}$ \\
\hline \multicolumn{6}{|l|}{ Infection specified by criteria: } \\
\hline By 10-14 day follow-up & $3(3)$ & $2(2)$ & $1.1(-4.7$ to 7.2$)$ & $2(2)$ & $1.0(-4.9$ to 7.1$)$ \\
\hline By 8 week follow-up & $3(3)$ & $2(2)$ & $1.1(-4.7$ to 7.2$)$ & $3(3)$ & $-0.1(-6.5$ to 6.2$)$ \\
\hline \multicolumn{6}{|l|}{ Infection specified by antibiotic use: } \\
\hline By 10-14 day follow-up & $8(9)$ & $2(2)$ & $6.5(-0.03$ to 14.2$)$ & $6(7)$ & $2.0(-6.3$ to 10.4$)$ \\
\hline By 8 week follow-up & $11(12)$ & $3(3)$ & $8.7(-9.0$ to 17.2$)$ & $9(10)$ & $2.0(-7.5$ to 11.4$)$ \\
\hline No of women who had any curettage* & $78(85)$ & $23(25)$ & 59.8 (46.7 to 69.5$)$ & $26(29)$ & 55.9 (42.6 to 66.1$)$ \\
\hline $\begin{array}{l}\text { No of women who had one or more unplanned } \\
\text { curettage } \dagger\end{array}$ & $2(2)$ & $23(25)$ & $-22.8(-32.7$ to -13.4$)$ & $6(7)$ & -4.5 ( -11.8 to 2.0$)$ \\
\hline \multicolumn{6}{|c|}{ Main reason for unplanned consultation resulting in unplanned curettage: } \\
\hline Excess bleeding & $2(2)$ & $7(8)$ & $-5.4(-12.9$ to 1.2$)$ & 0 & $2.2(-2.2$ to 7.6$)$ \\
\hline Pain & 0 & 0 & $0(-4.0$ to 4.0$)$ & 0 & $0(-4.1$ to 4.0$)$ \\
\hline Patient request & 0 & $8(9)$ & $-8.7(-16.2$ to -2.9$)$ & $2(2)$ & $-2.2(-2.2$ to 7.6$)$ \\
\hline Retained products on scan & 0 & $8(9)$ & $-8.7(-16.2$ to -2.9$)$ & $3(3)$ & $-3.3(-9.3$ to 1.2$)$ \\
\hline Other & 0 & 0 & $0(-4.0$ to 4.0$)$ & $1(1)$ & $-1.1(-6.0$ to 3.0$)$ \\
\hline Median (interquartile range) duration of bleeding (days) & $7(4-12)$ & $10(7-13.3)$ & & $9(6-14)$ & \\
\hline Blood transfusion & 0 & 0 & $0(-4.0$ to 4.0$)$ & $1(1)$ & $-1.1(-6.0$ to 3.0$)$ \\
\hline Extra analgesia taken & $12(13)$ & $21(23)$ & $-9.8(-20.8$ to 1.4$)$ & $17(19)$ & $-5.8(-16.6$ to 4.9$)$ \\
\hline
\end{tabular}

*Allocated, for failed medical induction, or unplanned.

†Excluding women who had curettage for failure of medical management protocol.

"extra analgesia" as a proxy measure to evaluate the need for analgesia by all three groups in the outpatient setting. The expectant management group received significantly more analgesia (table 2).

We found no difference between the three groups in the incidence of surgical complications in the women who had surgery. Surgical complications were reported in $2 \%(9 / 402), 1 \%$ (4/398), and $1 \%(4 / 398)$ of women allocated to receive surgical, expectant, and medical management respectively.

\section{Psychological and activities outcomes}

In all three groups the median time to return to usual daily activities was two days. Sick leave was also similar in all three groups-the median was nine days in the surgical group, eight days in the expectant group, and nine days in the medical group. No differences existed in anxiety or depression scores on the hospital anxiety and depression questionnaire six to eight weeks after miscarriage. Similarly, no differences existed in activities of daily living on any of the eight subscales of the UK SF-36.

\section{Discussion}

Gynaecologists have been taught that surgical curettage is necessary to prevent infection after miscarriage. In this trial, the infection rates after expectant, medical, and surgical management were not significantly different and were reassuringly low. This was in the absence of screening for infection and without the use of prophylactic antibiotics. Moreover, the incidence of presumed infection as measured by antibiotic prescription in the first 14 days was significantly lower in the expectant management group than in the surgical group. These data should be reassuring to people who have raised concern about the lack of evidence available for non-surgical treatment of miscarriage. ${ }^{34}$

The success rates in this trial were comparable to those in other trials of expectant management of incomplete miscarriage and early fetal demise. ${ }^{6}$ Observational studies, however, had suggested that higher success rates were achievable. ${ }^{22}{ }^{23}$ Some of these differences could be explained by the lack of a universal definition of ultrasound scan findings of incomplete miscarriage or the presence of retained products at follow-up. Current clini- cal practice is not to do an ultrasound scan to measure endometrial thickness after a surgical curettage. Therefore, more women than usual may have been diagnosed as having retained products of conception and advised to have subsequent surgical curettage. For medical management, the success of the treatment protocol was disappointing compared with the higher success rates in the observational studies on which we based the treatment protocol and other observational studies. ${ }^{19} 24$

Women are increasingly offered a choice of treatment for the management of miscarriage..$^{25}$ This study provides important data to enable women to be informed about their treatment choice. The ability of a unit to offer all three choices will depend on its facilities. The unplanned admission rate in women randomised to expectant management supports the advice from the Royal College of Obstetricians and Gynaecologists that expectant and medical management should be offered only in units where patients have access to 24 hour telephone advice and immediate admission can be arranged.$^{26}$ Expectant management seems to be particularly appropriate for incomplete miscarriage, with success rates of $75 \%$, although an emergency admission rate of up to $29 \%$ should be anticipated.

Medical management does not seem to offer greater success than expectant management when used to treat incomplete miscarriage, but it may offer an alternative management in early fetal demise. Allowing a longer time for products of conception to pass may increase the success rate. ${ }^{27}$ However, the increased time spent in hospital could be unattractive to women and care providers alike. Another option would be to use misoprostol in an outpatient setting. Randomised trials have shown that this is possible, with success rates of 72-93\%. ${ }^{13-15}$ 28-31 The optimum regimen for medical management is yet to be devised, and further research is needed to determine this, particularly in an outpatient setting. Surgical curettage still offers the greatest complete evacuation rate, the least risk of needing unplanned admission, and the shortest duration of bleeding. It should therefore continue to be offered as a management option, particularly to those women with early fetal demise.

Because of the challenges of recruiting women to a trial of expectant, medical, and surgical management of miscarriage of 
this size, such a trial seems unlikely to be repeated. This trial shows that infection rates, whatever the chosen management, are reassuringly low. Success rates of the three options may be higher than the MIST trial suggests, as women who choose a treatment option are likely to be more motivated to follow their chosen treatment to completion than are women who are randomised. ${ }^{32}$

We thank the Clinical Trials Service Unit, Oxford, for providing telephone randomisation and Sarah Ayers at the National Perinatal Epidemiology Unit, Oxford, for writing the data entry program and for providing data for analysis. We also thank Steering Committee members G Stirrat (Bristol), D Mant (Oxford), R Bender Attik (Miscarriage Association), and C Law (Southampton) for their guidance during the trial and Data Monitoring Committee members D Elbourne (London), D Jewell (Bristol), P Ewings (Taunton), and J Friend (Plymouth). A list of investigators and centres is on bmj.com.

Contributors: JT, PB, and LS prepared the manuscript. JT, RP, SV, and LS conceived the trial. LS was the trial grant lead. JT, PB, RP, MR, SV, and LS designed and coordinated the trial. JT, LS, and PB coordinated the data collection. PB did the statistical analysis. JT is the guarantor.

Funding: The MIST study was funded by a South and West NHS Executive research and development grant. A donation of $£ 20000$ was accepted from Exelgyn. Neither the NHS Executive nor Exelgyn had any role in the study design; collection, analysis, or interpretation of data; writing of the report; or the decision to submit the paper for publication.

Competing interests: The study group accepted a donation of $£ 20000$ from Exelgyn, the manufacturers of mifepristone. The authors have no other competing interests.

Ethical approval: Multicentre Research Ethics Committee (MREC/97/6/ 24) and local research ethics committee approval for each centre.

1 Nybo Andersen AM, Wohlfahrt J, Christens P, Olsen J, Melbye M. Maternal age and fetal loss: population based register linkage study. BMJ 2000;320:1708-12.

2 Chung TK, Lee DT, Cheung LP, Haines CJ, Chang AM. Spontaneous abortion: a randomized, controlled trial comparing surgical evacuation with conservative management using misoprostol. Fertil Steril 1999;71:1054-9.

3 Jurkovic D. Modern management of miscarriage: is there a place for non-surgical treatment? Ultrasound Obstet Gynecol 1998;11:161-3.

4 Cahill DJ. Managing spontaneous first trimester miscarriage. BMJ 2001;322:1315-6.

5 Chipchase J, James D. Randomised trial of expectant versus surgical management of spontaneous miscarriage. Br J Obstet Gynaecol 1997;104:840-1.

6 Nielsen S, Hahlin M. Expectant management of first-trimester spontaneous abortion Lancet 1995;345:84-6.

7 Wieringa-de Waard M, Vos J, Bonsel GJ, Bindels PJ, Ankum WM. Management of miscarriage: a randomized controlled trial of expectant management versus surgical evacuation. Hum Reprod 2002:17:2445-50.

8 De Jonge ET, Makin JD, Manefeldt E, De Wet GH, Pattinson RC. Randomised clinical trial of medical evacuation and surgical curettage for incomplete miscarriage. BMJ 1995;311:662.

\section{What is already known on this topic}

The most effective method of ensuring complete evacuation of retained products of conception after miscarriage is surgical curettage

Expectant management of incomplete miscarriage is effective, and evidence suggests that it is associated with lower rates of infection than surgical management

Medical management of miscarriage is effective, but little is known about infection rates

\section{What this study adds}

The risk of gynaecological infection after management of miscarriage by expectant, medical, and surgical methods is low $(2-3 \%)$

This large randomised controlled trial did not find a significant difference in infection between expectant, medical, and surgical management of miscarriage

The risk of unplanned hospital admission is highest with expectant management of miscarriage
9 Weeks A, Alia G, Blum J, Winikoff B, Ekwaru P, Durocher J, et al. A randomized trial of misoprostol compared with manual vacuum aspiration for incomplete abortion. Obstet Gynecol 2005;106:540-7.

10 Zhang J, Gilles JM, Barnhart K, Creinin MD, Westhoff C, Frederick MM. A comparison of medical management with misoprostol and surgical management for early pregnancy failure. N Engl J Med 2005;353:761-9.

11 Moodliar S, Bagratee JS, Moodley J. Medical vs. surgical evacuation of first-trimester spontaneous abortion. Int J Gynaecol Obstet 2005;91:21-6.

12 Demetroulis C, Saridogan E, Kunde D, Naftalin AA. A prospective randomized control trial comparing medical and surgical treatment for early pregnancy failure. Hum Reprod 2001;16:365-9.

13 Sahin HG, Sahin HA, Kocer M. Randomized outpatient clinical trial of medical evacuation and surgical curettage in incomplete miscarriage. Eur J Contracept Reprod Health Care 2001;6:141-4.

14 Muffley PE, Stitely ML, Gherman RB. Early intrauterine pregnancy failure: a randomized trial of medical versus surgical treatment. Am J Obstet Gynecol 2002;187:321-5.

15 Gronlund L, Gronlund AL, Clevin L, Andersen B, Palmgren N, Lidegaard O. Spontaneous abortion: expectant management, medical treatment or surgical evacuation. Acta Obstet Gynecol Scand 2002;81:781-2.

16 Hamilton-Fairley D, Donaghy J. Surgical versus expectant management of first-trimester miscarriage: a prospective observational study. In: Grudzinskas JG, O'Brien P, eds. Problems in early pregnancy: advances in diagnosis and management. London: RCOG Press, 1997:277-83.

17 Shelley JM, Healy D, Grover S. A randomised trial of surgical, medical and expectant management of first trimester spontaneous miscarriage. Aust $N \mathrm{ZJ}$ Obstet Gynaecol 2005;45:122-7.

18 Royal College of Radiologists and Royal College of Obstetricians and Gynaecologists. Guidance on ultrasound procedures in early pregnancy. London: Royal College of Radiologists, 1995 .

19 Henshaw RC, Cooper K, El-Refaey H, Smith NC, Templeton AA. Medical management of miscarriage: non-surgical uterine evacuation of incomplete and inevitable spontaneous abortion. BMJ 1993;306:894-5.

20 El-Rafaey H, Dhamnasekar R, Abdalla M, Calder L, Templeton A. Induction of abortion with mifepristone (RU 486) and oral or vaginal misoprostol. $N$ Engl J Med 1995;332:983-7

21 World Health Organisation Task Force on Post-ovulatory Methods of Fertility Regulation. Termination of pregnancy with reduced doses of mifepristone. BMJ 1993;307:532-7.

22 Sairam S, Khare M, Michailididis G, Thilaganathan B. The role of ultrasound in the expectant management of early pregnancy loss. Ultrasound Obstet Gynecol 2001;17:506-9.

23 Luise C, Jermy K, May C, Costello G, Collins WP, Bourne TH. Outcome of expectant management of spontaneous first trimester miscarriage: observational study. $B M J$ 2002;324:873-5.

24 Chung TK, Leung P, Cheung LP, Haines CJ, Chang AM. A medical approach to management of spontaneous abortion using misoprostol. Acta Obstet Gynecol Scand 1997;76:248-51.

25 Bradley E, Hamilton-Fairley D. Managing miscarriage in early pregnancy assessment units. Hospital Medicine 1998;59:451-6.

26 Guidelines and Audit Committee of the Royal College of Obstetricians and Gynaecologists. The management of early pregnancy loss: clinical green top guidelines. London: RCOG, 2000

27 Chung T, Leung P, Cheung LP, Haines C, Chang AM. A medical approach to management of spontaneous abortion using misoprostol: extending misoprostol treatment to a maximum of 48 hours can further improve evacuation of retained products of cona maximum of 48 hours can further improve evacuation of retained product
ception in spontaneous abortion. Acta Obstet Gynecol Scand 1997;76:248-51.

28 Nielsen S, Hahlin M, Platz-Christensen J. Randomised trial comparing expectant with medical management for first trimester miscarriages. $\mathrm{Br} J$ Obstet Gynaecol 1999;106:804-7.

29 Ngai SW, Chan YM, Tang OS, Ho PC. Vaginal misoprostol as medical treatment for first trimester spontaneous miscarriage. Hum Reprod 2001:16:1493-6.

30 Wood SL, Brain PH. Medical management of missed abortion: a randomized clinical trial. Obstet Gynecol 2002;99:563-6.

31 Bagratee JS, Khullar V, Regan L, Moodley J, Kagoro H. A randomized controlled trial comparing medical and expectant management of first trimester miscarriage. Hum Reprod 2004;19:266-71.

32 Brewin CR, Bradley C. Patient preferences and randomised clinical trials. BMJ 1989;299:313-5.

(Accepted 9 March 2006)

doi $10.1136 /$ bmj.38828.593125.55

Southmead Hospital, Westbury-on-Trym, Bristol BS10 5NB

$\mathrm{J}$ Trinder specialist registrar in obstetrics and gynaecology

$\mathrm{S}$ Vyas consultant obstetrician and gynaecologist

National Perinatal Epidemiology Unit, University of Oxford, Oxford OX3 7LF P Brocklehurst director

Royal United Hospital, Bath BA1 3NG

$\mathrm{R}$ Porter consultant obstetrician and gynaecologist

Gloucestershire Royal NHS Hospital, Gloucester GL1 3NN

M Read consultant obstetrician and gynaecologist

East Somerset Research Consortium, West Coker, Somerset BA22 9AH

L Smith general practitioner

Correspondence to: J Trinder, Consultant in Maternal Medicine and Obstetrics, Department of Obstetrics and Gynaecology, St Michael's Hospital, Southwell St, Bristol BS2 8EG jo.trinder@bristol.ac.uk 